\title{
Experimental and Numerical Analysis of Springback Behavior of Aluminum Alloys
}

\author{
J. Slota, ${ }^{\mathrm{a}, 1}$ M. Šiser, ${ }^{\mathrm{a}, 2}$ and M. Dvorák ${ }^{\mathrm{b}, 3}$ \\ a Technical University of Košice, Faculty of Mechanical Engineering, Institute of Material and \\ Technological Engineering, Košice, Slovakia \\ ${ }^{\mathrm{b}}$ Brno University of Technology, Faculty of Mechanical Engineering, Brno, Czech Republic \\ 1 jan.slota@tuke.sk \\ 2 marek.siser@tuke.sk \\ ${ }^{3}$ dvorak.m@fme.vutbr.cz
}

Presented work deals with springback behavior of two different aluminum alloys, one falling into 5th series (AW-5754 H22) with a thickness of $0.8 \mathrm{~mm}$ and other from 6th series (AW-6082 T6) with 1.0 mm thickness. These materials are used for their various applications and hardening process. The springback behavior was investigated by U-bending test. Bending tool was graduated jig with rollers and experiment was performed on $R 11$ and R17 radii. The first series of specimens were oriented in a parallel direction and the other in a direction perpendicular to the rolling direction. Experimental results were measured with MATLAB measuring method and compared with finite element calculation carried out in PAM-STAMP. Influence of different yield functions was also examined.

Keywords: finite element method (FEM), ANSYS, clinching, three sheets, steel, mechanical joining.

Introduction. Sheet metal bending is one of the most common forming process, widely used in various production areas to create simple profiles (e.g., bending to U- or V-shape) from a flat sheet, using affordable methods. Tekiner [1] defined sheet metal bending as a homogenous material deformation around axis located in the neutral plane and orthogonal to the length direction of the specimen. Even though metal bending is basically simple process it is also very difficult, in particular as regards to fragile, hard to bend materials as titanium or aluminum alloys. These materials are often affected by springback, which is difficult to compensate. Springback is mostly affected by factors such as material properties (elastic modulus, Poisson's ratio, strain-hardening exponent, yield strength or material anisotropy), friction coefficient, clearance between punch and die, blankholder force, die and punch radii, bending radii, etc. [2-6]. However, aluminum alloys often display high ratio of yield stress to elastic modulus, which also significantly affects springback. Springback usually leads to change in geometry of stamped part which is to be compensated, thereby leading to a rise in production costs [1]. This effect is most commonly compensated by over-bending of stamped part. Many currently available software provides the possibility to sophisticated compensation of springback [7]. Many authors [8-13] deals this by using special modules in various FEM software. In recent years, a lot of research has been done in this area, and multiple authors have analyzed the springback problem from many different perspectives. Thus, authors [8] considered the bending into U-shape with a blankholder, while researchers [9] studied the impact of used material on the prediction accuracy of numerical simulation of HSLA sheets. Authors [10, 12, 13] investigated different materials, including $\mathrm{Ti}$ and $\mathrm{Al}$ alloys, and the springback phenomena occurring in them. In study [11], three different materials has been used, namely TRIP RAK 40/70 UHS steel, HSLA 220PD AHS steel, and DQ category DC06 alloy, which were subjected to cyclic loading with the further Bauschinger effect investigation. This study 
deals with exploration of springback effect in two aluminum alloys, which are often used in automotive industry. The springback effect can also depend on the specimen orientation. Specimens with loading axes oriented parallelly and perpendicularly to the rolling direction can be distinguished by different springback angles.

Experimental Procedure. The springback effect in aluminum specimens bent using an experimental graduated bending jig with rollers was examined. Each specimen was bent to the angle of $180^{\circ}$, and after its unloading the springback angle was measured. The measured results were compared with the numerical simulation data and with the results of work [11]. In these tests, the impact of rolling direction of the bent specimen on the springback behavior was also investigated. Two different materials, namely AW-6082 T6 and aluminum alloys different content with magnesium and silicon, which are frequently used in automotive industry for fabrication of car body parts, were used in this experiment. It is known that springback is strongly dependent on the type of material used [14]. The AW-6082 T6 alloy specimens were in the state after solution heat treatment followed by artificial aging and had a thickness $1.0 \mathrm{~mm}$, while those of AW-5754 H22 were workhardened (1/4 hard) and partly annealed, and their thickness was $0.8 \mathrm{~mm}$. The mechanical properties and rolling directions of these specimens are shown in Tables 1 and 2, respectively. Rectangular-shaped specimens with the dimensions $20 \times 120 \mathrm{~mm}$ were used for the experiment.

$\mathrm{T}$ a $\mathrm{b} 1 \mathrm{e} 1$

Mechanical Properties of AW-6082 T6

\begin{tabular}{|c|c|c|c|c|c|c||}
\hline $\begin{array}{c}\text { Rolling } \\
\text { direction } \\
\text { (deg) }\end{array}$ & $\begin{array}{c}R_{p 0.2}, \\
\mathrm{MPa}\end{array}$ & $\begin{array}{c}R_{m}, \\
\mathrm{MPa}\end{array}$ & $\begin{array}{c}A_{80}, \\
\%\end{array}$ & $n$ & $\begin{array}{c}C_{m}, \\
\mathrm{MPa}\end{array}$ & $r$ \\
\hline 0 & 314 & 342 & 13.7 & 0.087 & 456.12 & 0.528 \\
\hline 45 & 308 & 337 & 14.2 & & & 0.657 \\
\hline 90 & 313 & 341 & 12.0 & & & 0.509 \\
\hline
\end{tabular}

$\mathrm{T}$ a b 1 e 2

Mechanical Properties of AW-5754 H22

\begin{tabular}{|c|c|c|c|c|c|c||}
\hline $\begin{array}{c}\text { Rolling } \\
\text { direction } \\
(\text { deg })\end{array}$ & $\begin{array}{c}R_{p 0.2}, \\
\mathrm{MPa}\end{array}$ & $\begin{array}{c}R_{m}, \\
\mathrm{MPa}\end{array}$ & $\begin{array}{c}A_{80}, \\
\%\end{array}$ & $n$ & $\begin{array}{c}C_{m}, \\
\mathrm{MPa}\end{array}$ & $r$ \\
\hline 0 & 165 & 250 & 14.2 & 0.196 & 410.69 & 0.545 \\
\hline 45 & 155 & 239 & 20.8 & & & 1.060 \\
\hline 90 & 160 & 246 & 19.2 & & & 0.786 \\
\hline
\end{tabular}

The experimental procedure is shown in Fig. 1. To measure the springback angle, two different bend radii $R 11$ and $R 17$ were used. Specimens were bent to the angle of $180 \%$ around the die, then unloaded, and the springback angle was measured. The geometry of the experimental graduated bending jig with rollers is shown in Fig. 2.

For comparison purpose, the same methodology was used as in work [11]. To measure the springback angle, the MATLAB application was used, wherein five points per each arm of specimen were applied to construct a straight line and simulated the inclination angles. The test results were compared with the numerical simulation ones obtained using an explicit FEM code. The parameters used in the numerical simulation are listed in Table. 3. 
$\mathrm{T}$ a b 1 e 3

Parameters Defined in Preprocessing of Numerical Simulation

\begin{tabular}{||c|c|c|c||}
\hline Parameter & Value & Parameter & Value \\
\hline Mesh type & Quadrilateral & Element type & Shell \\
\hline Initial mesh size & $17 \mathrm{~mm}$ & Element formulation & E-P shell \\
\hline Level of refinement & 4 & Yield curve & Hill 90 \\
\hline Mesh size after refinement & $1.06 \mathrm{~mm}$ & Hardening curve & Krupkowski \\
\hline Number of integration points & 11 & Tool mesh & $17 \mathrm{~mm}$ \\
\hline
\end{tabular}

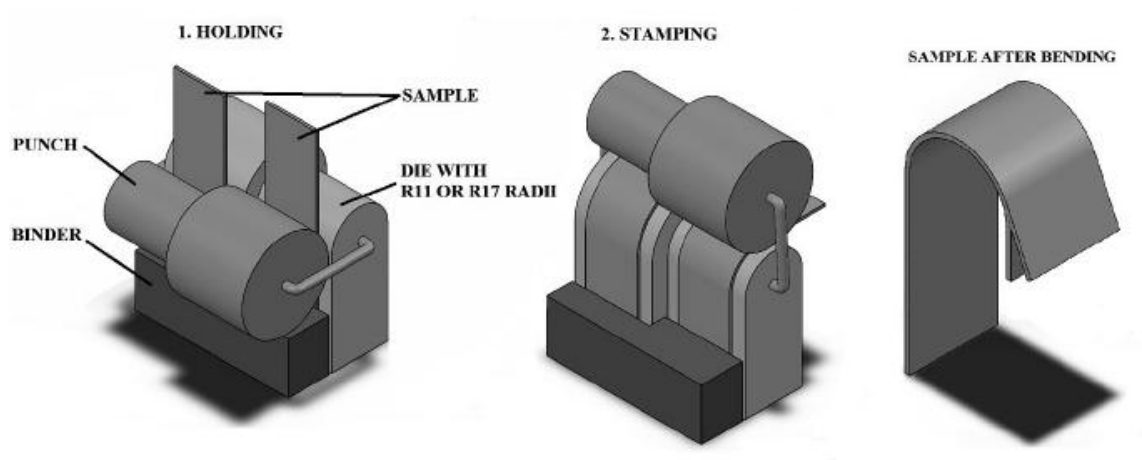

Fig. 1. Schematic illustration of the bending process.

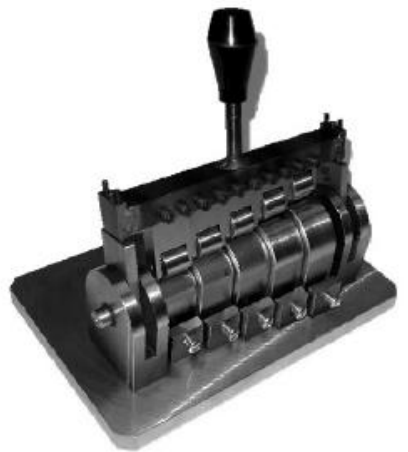

Fig. 2. Experimental graduated bending jig with rollers.

For aluminum alloys, the Hill90 yield function is considered to be the most appropriate [15]. It is based on the nonquadratic transition function and, in order to construct this function, values from the uniaxial tensile and biaxial tests are required. This function is defined by equation [15]:

$$
\left(\frac{\sigma_{1}}{\sigma_{2}}\right)^{2}+\left(\frac{\sigma_{2}}{\sigma_{90}}\right)^{2}+\left[p+q+c-\frac{p\left(\sigma_{1}+\sigma_{2}\right)}{\sigma_{b}}\right] \frac{\sigma_{1} \sigma_{2}}{\sigma_{0} \sigma_{90}}=1,
$$

where $\sigma_{0}$ is the uniaxial tensile stress in the rolling direction (MPa), $\sigma_{90}$ is the uniaxial tensile stress in the direction normal to the rolling direction (MPa), $\sigma_{b}$ is stress under balanced biaxial loading conditions (MPa), while $c, p$, and $q$ are parameters defined as in [15]: 


$$
\begin{gathered}
c=\frac{\sigma_{0}}{\sigma_{90}}+\frac{\sigma_{90}}{\sigma_{0}}-\frac{\sigma_{0} \sigma_{90}}{\sigma_{b}^{2}}, \\
\left(\frac{1}{\sigma_{0}}+\frac{1}{\sigma_{90}}-\frac{1}{\sigma_{b}}\right) p=\frac{2 R_{0}\left(\sigma_{b}-\sigma_{90}\right)}{\left(1+R_{0}\right) \sigma_{0}^{2}}-\frac{2 R_{90} \sigma_{b}}{\left(1+R_{90}\right) \sigma_{90}^{2}}+\frac{c}{\sigma_{0}}, \\
\left(\frac{1}{\sigma_{0}}+\frac{1}{\sigma_{90}}-\frac{1}{\sigma_{b}}\right) q=\frac{2 R_{90}\left(\sigma_{b}-\sigma_{0}\right)}{\left(1+R_{90}\right) \sigma_{90}^{2}}-\frac{2 R_{0} \sigma_{b}}{\left(1+R_{0}\right) \sigma_{0}^{2}}+\frac{c}{\sigma_{90}} .
\end{gathered}
$$

Here $R_{0}$ and $R_{90}$ are the anisotropy values for the uniaxial tension in the rolling direction and in the in-plane direction perpendicular to the rolling direction, respectively.

The above yield function was used in combination with the Krupkowski hardening law expressed by the following equation [16]:

$$
\sigma=K\left(\varepsilon_{p}+\varepsilon_{o}\right)^{n}
$$

where $\varepsilon_{p}$ is the plastic strain, $\varepsilon_{o}$ is the offset strain, $n$ is the strain-hardening exponent, and $K$ is the material constant (MPa).

The applied yield functions and hardening curves for both materials are shown in Fig. 3.

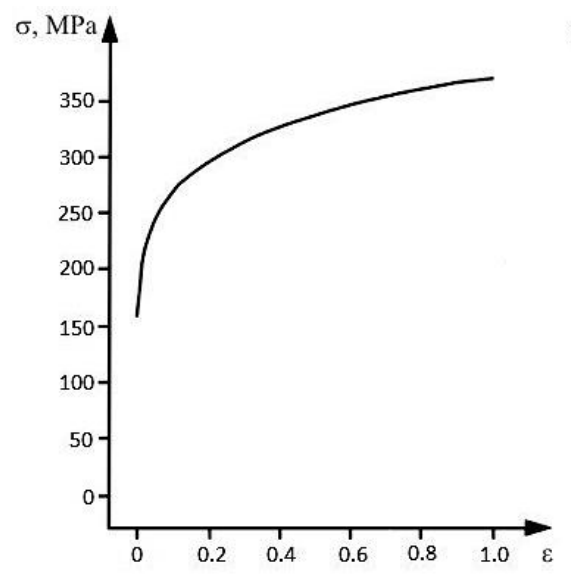

$\mathrm{a}$

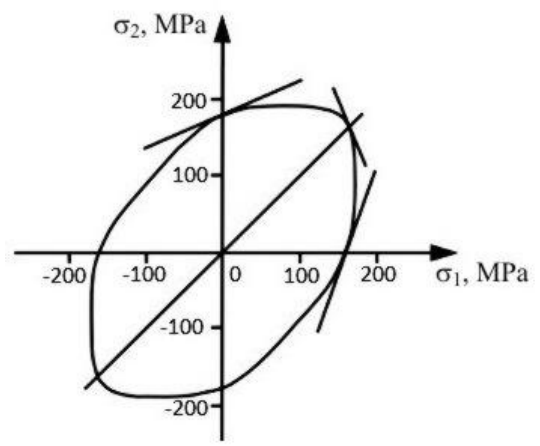

$\mathrm{c}$

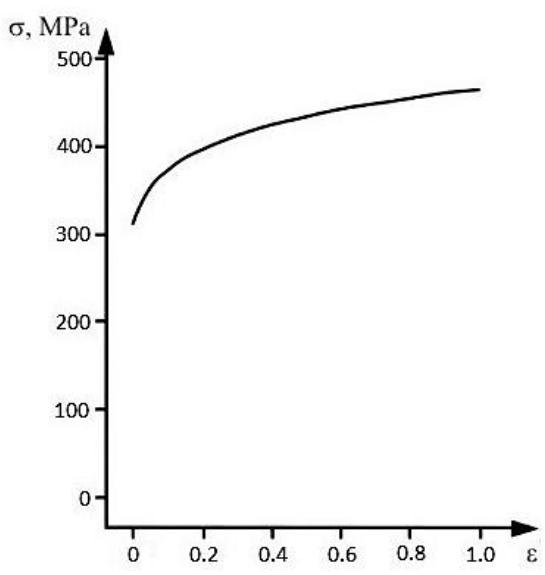

$\mathrm{b}$

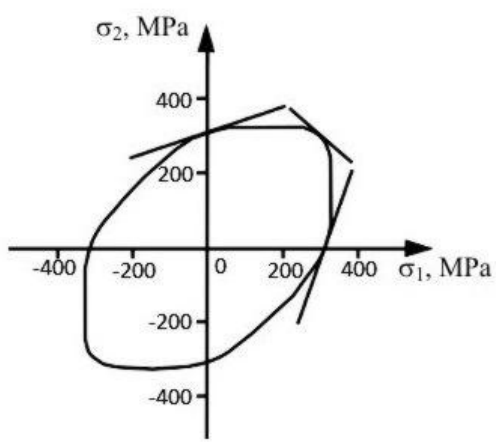

d

Fig. 3. The Krupkowski hardening curves for AW-5754 H22 (a) and AW-6082 T6 (b), Hill90 yield functions for AW-5754 H22 (c) and AW-6082 T6 (d). 
Results and Discussion. Tables 4 and 5 list the experimental results of springback compared with numerical simulation. The bending test was simulated according to the experimental setup shown in Fig. 1. To examine the influence of rolling direction on the springback angles, specimens were cut differently to the rolling direction. The first series of specimens were cut in the direction parallel to the rolling one (further RD) and the second series were cut in the direction perpendicular to it (further TD). Configurations of bent specimens after springback are shown in Fig. 4.

T a b 1 e 4

Results of Springback for AW-5754 H22

\begin{tabular}{|c|c|c|}
\hline \multicolumn{3}{|c|}{ Die radius $R 11$} \\
\hline $\begin{array}{c}\text { Rolling } \\
\text { direction }\end{array}$ & Experiment & Simulation \\
\hline RD & 35.52 & 32.14 \\
\hline TD & 37.83 & 34.92 \\
\hline \multicolumn{3}{|c|}{ Die radius $R 17$} \\
\hline $\begin{array}{c}\text { Rolling } \\
\text { direction }\end{array}$ & Experiment & Simulation \\
\hline RD & 39.22 & 36.25 \\
\hline TD & 41.87 & 38.72 \\
\hline
\end{tabular}

T a b 1 e 5

Results of Springback for AW-6082 T6

\begin{tabular}{||c|c|c||}
\hline \multicolumn{3}{|c||}{ Die radius $R 11$} \\
\hline $\begin{array}{c}\text { Rolling } \\
\text { direction }\end{array}$ & Experiment & Simulation \\
\hline RD & 38.55 & 33.83 \\
\hline TD & 37.40 & 32.27 \\
\hline \multicolumn{3}{|c||}{ Die radius $R 17$} \\
\hline $\begin{array}{c}\text { Rolling } \\
\text { direction }\end{array}$ & Experiment & Simulation \\
\hline RD & 52.09 & 47.33 \\
\hline TD & 48.15 & 42.71 \\
\hline
\end{tabular}

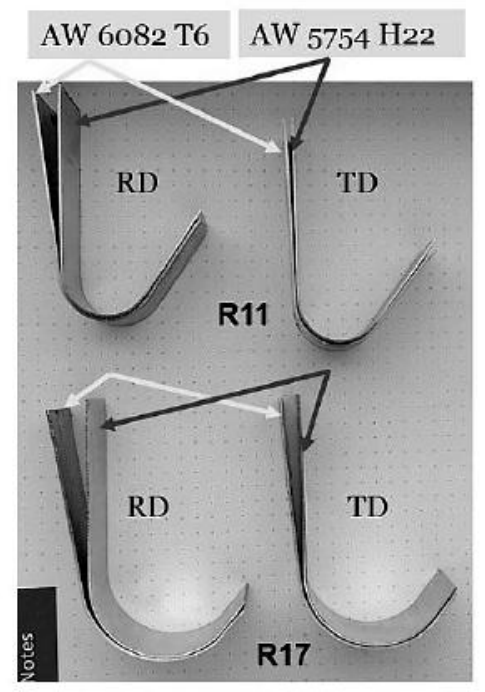

Fig. 4. Configurations of bent specimens after springback.

The comparison of experimental results with the numerical simulation shows that the calculated springback values are always lower than the experimental results. This occurs due to the used material model in FEM code. If we use the experimental results from [11] instead of the original ones, the differences will be even more significant:the higher strength of material the higher the difference. This result is affected by the applied yield function. In this study, the Hill90 plasticity condition was used, which is more suitable for special steels and alloys [10]. The graphical representation of this yield function, in comparison with several others, is presented in Fig. 5. The discrepancy between test and 


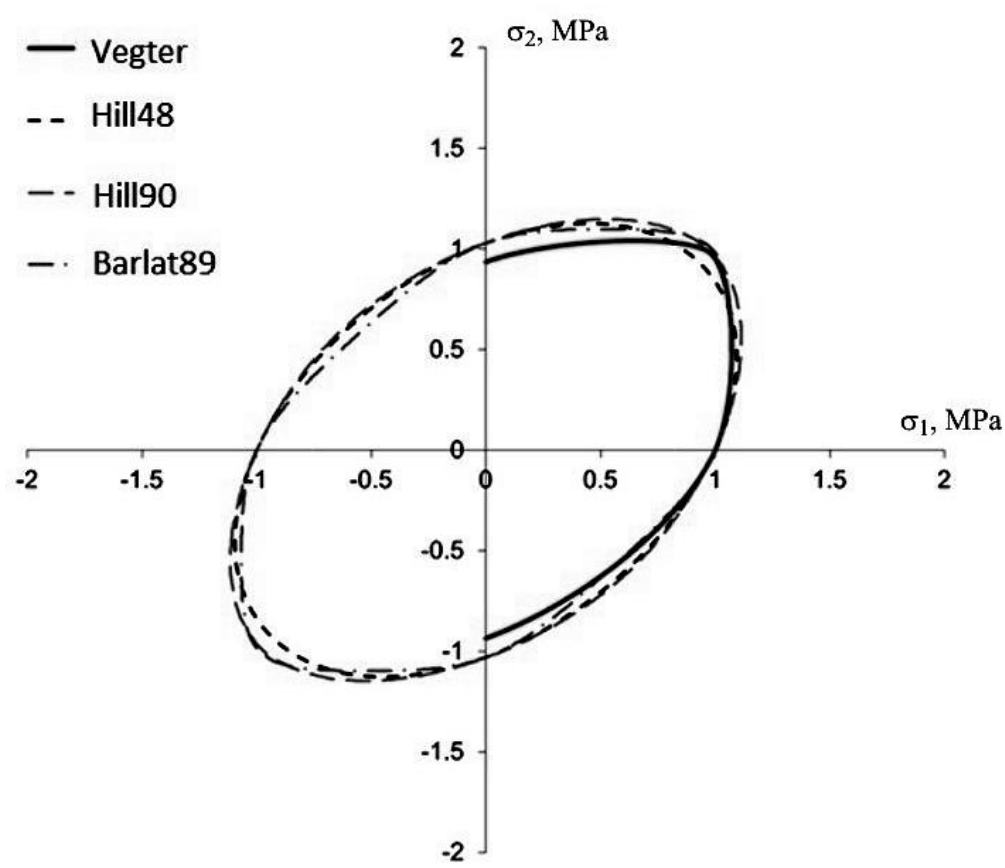

Fig. 5. Comparison of different yield functions for material AW-5754 H22.

calculated results is also influenced by the used hardening curve. In the mathematical description of the Krupkowski hardening law via Eq. (5), the elastic deformation component also appears in the formulation, and although it is much smaller than the plastic one, it is important in the FEM simulation of the springback [10]. Meanwhile, the Hill48 yield function was used in [11] for TRIP steel in combination with the Hollomon hardening curve, which also contribute to large deviations between the experimental results and numerical simulation data.

The above influence of the yield function used in the numerical simulation on the calculated results was investigated for AW-5754 H22 alloy. Two different yield functions were used in the numerical simulation, namely, isotropic Hill48 and orthotropic Hill90 yield functions. The former one considers anisotropy in all directions $(r=1)$, while the latter (Hill90) function is described by the Lankford coefficients, which are different in all directions. Therefore, differences in the equivalent stress are minimal in the RD direction, but quite considerable in the TD direction. The respective results shown in Fig. 6 indicate that the orthotropic material model Hill90 provides a better correlation with the experimental springback results than the isotropic Hill48 one. In case of AW-5754 H22 alloy, which is age-hardened, one can observe that springback efffect for specimens with the orientation parallel to the rolling direction (RD) is less pronounced than for specimens oriented perpendicular to the rolling direction (TD). The respective difference in the equivalent stresses was $7.5 \%$ for RD specimen with $R 11$ radii, $39 \%$ for TD specimen with $R 11$ radii, $10.6 \%$ for $\mathrm{RD}$ specimens with $R 17$ radii, and 36\% for TD specimen with $R 17$ radii. On the other hand, for AW-6082 T6 alloy, higher springback angles are observed in $\mathrm{RD}$ specimens. The difference in the equivalent stress for $R 11$ radii was $2.2 \%$ in $\mathrm{RD}$ and $2.5 \%$ in TD cases. For $R 17$ radii, the respective differences were $3.7 \%$ in $\mathrm{RD}$ and $1-3 \%$ in TD cases. Besides the fact that AW-6082 T6 alloy specimens had higher thickness and strength than AW-5754 H22 ones, this material was heat-treated, and its higher strength invoked a stronger springback effect (Fig.7). In addition, during its heat treatment process, the so-called Guinier-Preston zones (GPZ) were created by the segregation. These areas 

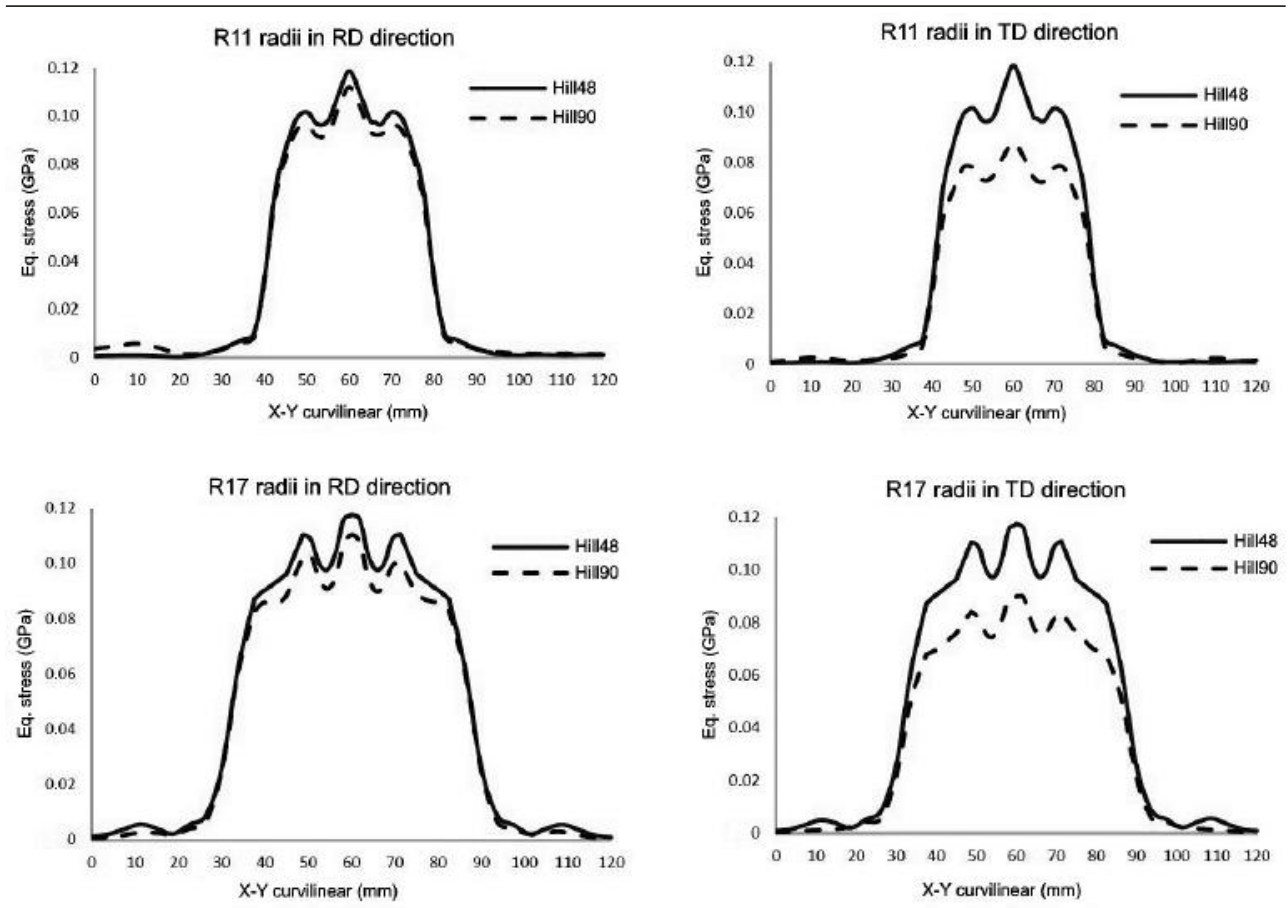

Fig. 6. Influence of yield function on the equivalent stresses after springback.

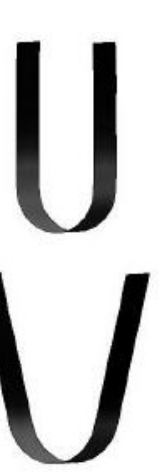

AW-5754 H22 RD
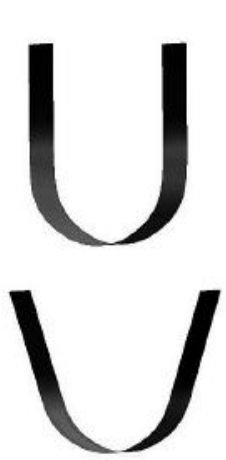

AW- 5754 H2Z KD
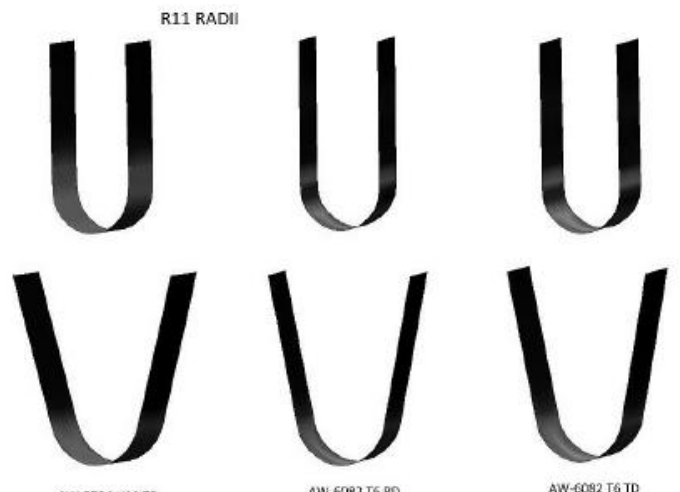

R17 RADII
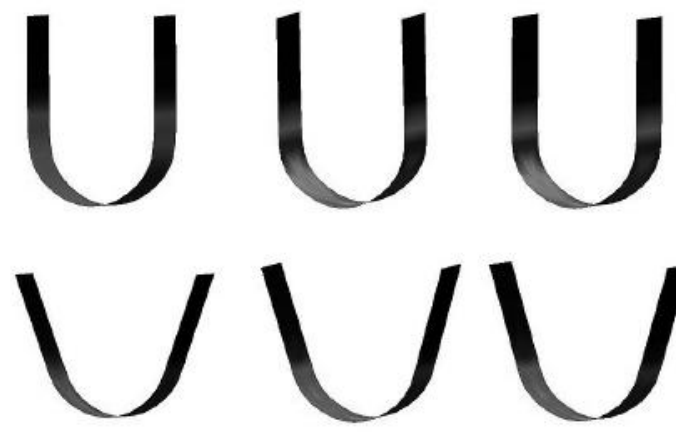

AW- 6082 T6 RD

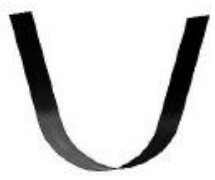

AW-GDB2 T6 TO

$0.360 \mathrm{GPa}$

Fig. 7. Results of numerical simulation for two materials, radii, and directions. 

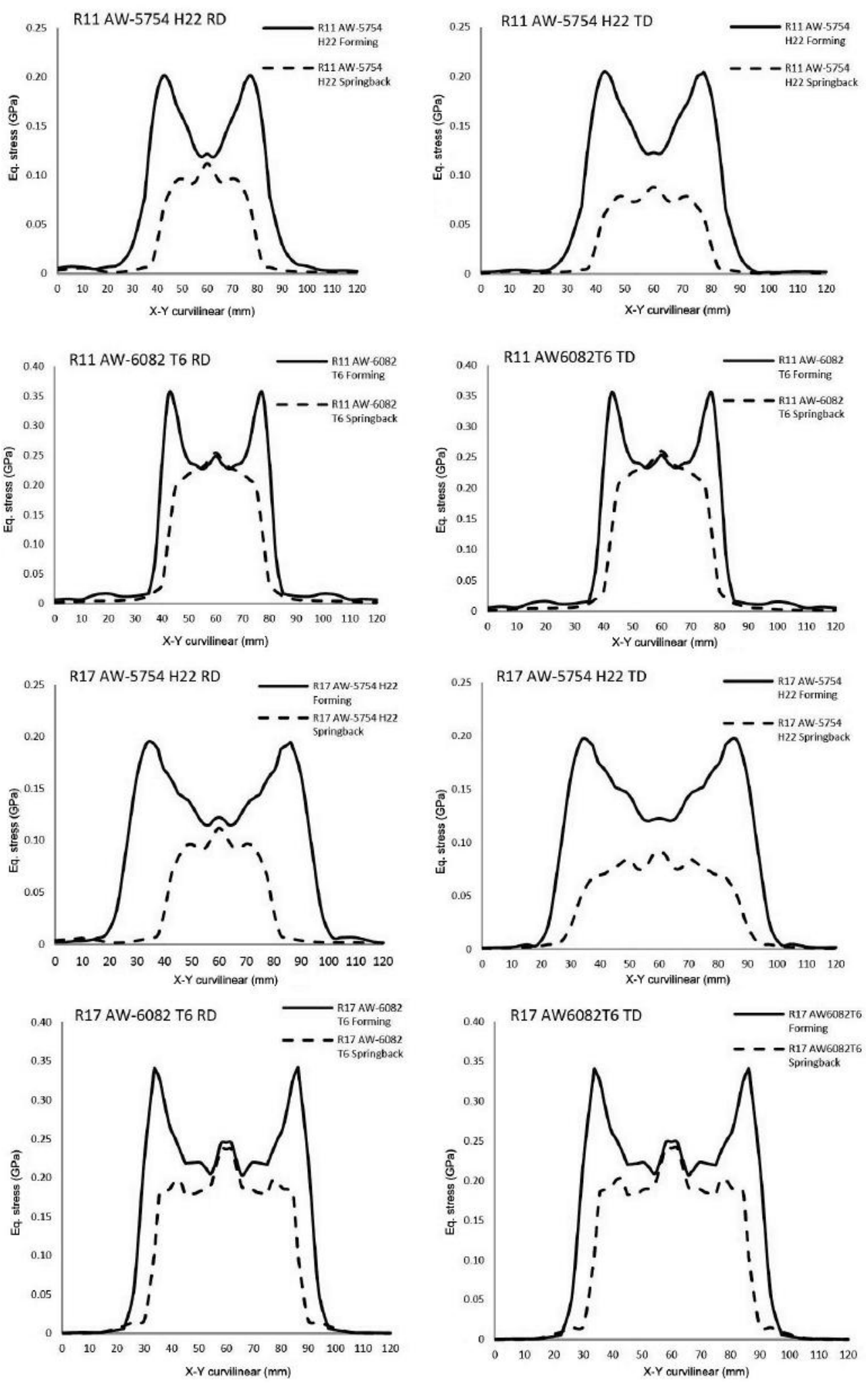

Fig. 8. Comparison of equivalent stresses before and after springback. 
have increased concentration of intermediate phase in solid form. Since GPZs are coherent with the solid solution, they create grid stresses that increase the hardness and strength of the material in the direction parallel to the rolling one.

Figure 8 shows the equivalent stresses in specimens before and after springback. The specimens were cut in the center of their width (in the middle layer). It is easy to see the results of the stress drop after springback, which invoked the stress relaxation in the specimen under study. For AW-6082 T6, the patterns of stresses in RD and TD are very similar. For AW-5754 H22, there is a visible stress drop in the TD case, in contrast to RD one. This is due to the material structure shown in Fig. 9. AW-57584 H22 is $\mathrm{Al}+\mathrm{Mg}$ alloy, while a higher content of $\mathrm{Mg}$ cause the creation of $\mathrm{Mg}_{5} \mathrm{Al}_{8}$ intermetalical phase in the grain boundaries, and the generation of strains in the material microstructure. The precipitation process has a negative effect on the mechanical properties, especially strength. On the other hand, the presence of $\mathrm{Mg}$ and $\mathrm{Si}$ in the alloy AW-6082 $\mathrm{T} 6$ alloy leads to the formation of $\mathrm{Mg}_{2} \mathrm{Si}$ precipitates, which improves the material strength.

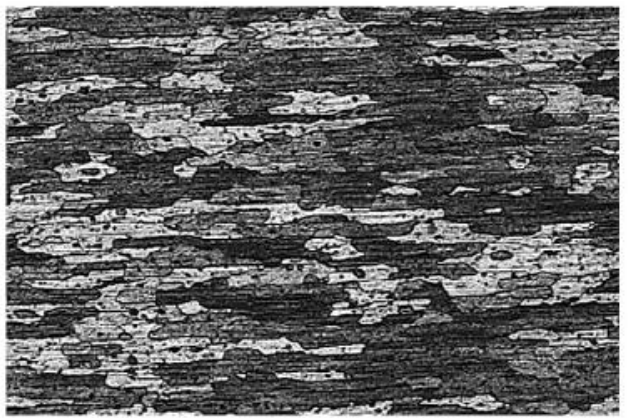

a

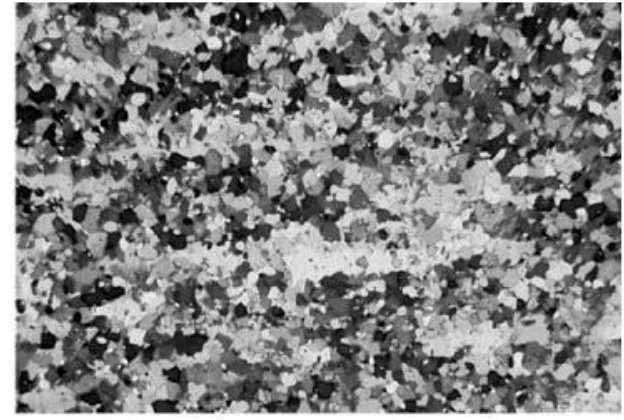

$\mathrm{b}$

Fig. 9. Microstructure of AW-6082 T6 (a) and AW-5754 H22 (b).

Conclusions. In this study, the springback behavior of aluminum sheets was investigated using the FEM simulation and static bending tests. The most important findings can be concluded as follows:

1. The application of isotropic yield function yields similar calculation results as that of orthotropic yield function for specimens with cutting direction parallel to rolling one (RD), but different resultys for the perpendicular direction (TD). In the latter case, the equivalent stresses estimated via the isotropic model are higher than those obtained via the orthotropic one, which results in a larger deviation of simulated and experimental data. To achieve a better calculation accuracy, the application of more advanced yield functions is expedient.

2. A more pronounced springback effect was observed in the AW-6082 T6 alloy, in contrast to AW-5754 H22, which had a lower strength. For both materials, the increase in the die radius caused a stronger sprigback effect. This is attributed to the equivalent stresses, which are lower for smaller die radii. The results obtained also depend on the orientation of specimens to the rolling direction. For AW-5754 H22 alloy, greater springback angle was measured in TD case, than in RD one, while AW-6082 T6 alloy exhibited an opposite trend.

3. For AW-6082 T6, the patterns of stress distribution in RD and TD specimens are very similar. For material AW-5754 H22, there was a visible stress drop in the TD specimens, in contrast to RD case. The material structure and type of hardening are shown to control this effect.

4. Although measured and simulated data exhibited a good fit, the applied material model has a vital effect on the springback angle computation results. To improve the 
calculation accuracy, modern material models with comprehensive hardening laws are required.

Acknowledgments. This contribution is the result of project APVV-14-0834 implementation.

1. Z. Tekiner, "An experimental study on the examination of springback of sheet metals with several thicknesses and properties in bending dies," J. Mater. Process. Tech., 145, 109-117 (2004).

2. Y. E. Ling, H. P. Lee, and B. T. Cheok, "Finite element analysis of springback in L-bending of sheet metal," J. Mater. Process. Tech., 168, No. 2, 296-302 (2005).

3. N. Nanu and G. Brabie, "Analytical model for prediction of springback parameters in the case of $U$ stretch-bending process as a function of stresses distribution in the sheet thickness," Int. J. Mech. Sci., 64, 11-21 (2012).

4. R. H. Wagoner, H. Lim, M. G. Lee, et al., "Advanced issues in springback," Int. J. Plasticity, 45, 3-20 (2013).

5. C. J. Su, G. H. Zhang, S. M. Guo, et al., "Influence of friction on springback of quadrangle parts bending," Adv. Mater. Res., 217-218, 619-624 (2011).

6. Y. Hu, Simulating the Die Gap Effect on Springback Behavior in Stamping Processes, SAE Technical Paper 2000-01-1111 (2000), doi: 10.4271/2000-01-1111.

7. Springback Compensation with AutoForm Version 4.1, EuroBlech (2006).

8. W. Phanitwonga and S. Thipprakmasa, "FE-analysis of channel width effects on spring-back characteristics in the U-bending process," Procedia Engineer., 183, 17-22 (2017).

9. H. L. Dai, H. J. Jiang, T. Dai, et al., "Investigation on the influence of damage to springback of U-shape HSLA steel plates," J. Alloy. Compd., 708, 575-586 (2017).

10. A. Gisario, M. Barletta, and S. Venettacci, "Improvements in springback control by external force laser-assisted sheet bending of titanium and aluminum alloys," Opt. Laser Technol., 86, 46-53 (2016).

11. J. Slota, M. Jurčišin, and M. Dvorák, "Experimental and numerical analysis of springback prediction in U-bendings of anisotropic sheet metals," Zeszyty Naukowe Politechniki Rzeszowskiej, 288, 525-533 (2013).

12. J. Zhou, B. Wang, J. Lin, and L. Fu, "Optimization of an aluminum alloy anticollision side beam hot stamping process using a multi-objective genetic algorithm," Arch. Civ. Mech. Eng., 13, No. 3, 401-411 (2013).

13. A. Zajkani and H. Hajbarati, "Investigation of the variable elastic unloading modulus coupled with nonlinear kinematic hardening in springback measuring of advanced high-strength steel in U-shaped process," J. Manuf. Process., 25, 391-401 (2017).

14. J. Slota, M. Jurčišin, and E. Spišák, "Numerical and experimental springback determination of sheet metals in an air bending process," Acta Metall. Slovaca, 18, No. 4, 200-209 (2012).

15. S. Bruschi, T. Altan, D. Banabic, et al., "Testing and modelling of material behaviour and formability in sheet metal forming," CIRP Ann. - Manuf. Techn., 63, 727-749 (2014).

16. C. Arwidson, Numerical Simulation of Sheet Metal Forming for High Strenght Steels, Luleå University of Technology, Luleå (2005). 